\title{
The effects of sodium hydroxide and potassium permanganate treatment on roughness of coconut fiber surface
}

\author{
Muhammad Arsyad ${ }^{1, *}$ and Rudy Soenoko ${ }^{2}$ \\ ${ }^{1}$ Mechanical Engineering Department,Politeknik Negeri Ujung Pandang, 90245 Jalan Perintis \\ Kemerdekaan Km.10 Makassar, Indonesia \\ ${ }^{2}$ Mechanical Engineering Department, Brawijaya University, 65145 Malang, Indonesia
}

\begin{abstract}
The purpose of this study was to determine the grade of roughness of coconut fiber surface as result of sodium hydroxide and potassium permanganate treatment. Research stages are soaking for 3 hours, testing, and data processing. Coconut fiber is soaked in $5 \%, 10 \%$, $15 \%, 20 \%$ sodium hydroxide solution. Then soaked in $0.25 \%, 0.5 \%$, $0.75 \%$ and $1 \%$ potassium permanganate solution. After that, the coconut fiber is dried in the oven at $90{ }^{\circ} \mathrm{C}$ for 5 hours. Thereafter, measurement of surface roughness. The measurement of surface roughness was did in two methods namely SEM, and surface roughness gauge. Based on the results of the tests, it was concluded that the higher concentrations of sodium hydroxide and potassium permanganate solutions gave higher grades of surface roughness compared with untreated fibers.
\end{abstract}

\section{Introduction}

As one of the green plants, natural fiber contains the main elements of lignin, cellulose, and hemicellulose. Lignin is a macromolecular polyphenol compound whereas cellulose and hemicellulose are polysaccharide compounds. Natural fibers are also hydrophilic, meaning they are easy to absorb water [1] [2]. This will result in low of bonding strength between natural fibers and matrix, in addition to fiber surfaces still containing impurities and other elements [3]. However, the use of natural fibers as a composite reinforcer is still being studied and researched because natural fibers have several advantages such as light weight, large quantities, elasticity, low production cost, and no environmental pollution [4]. Commonly in studied used natural fibers are bamboo, banana, pineapple, coconut, palm fiber [5].

A method that can be applied to lignocellulosic materials to obtain good materials, ie chemical, physical, and microbiological methods. The most common method used to improve the surface of natural fibers is chemical treatment. This method is easier, more effective, faster, and does not use too much energy [6].

The chemical treatment provided to the natural fibers serves to clean the impurities and other elements present on the surface of the natural fibers in order to tighten the surface of the fiber and matrix so as to increase the strength of the bond between the matrix and the fibers [7].

\footnotetext{
Corresponding author: arsyadhabe@poliupg.ac.id
} 


\section{Material and methods}

The materials used are coconut fiber, $\mathrm{NaOH}$ solution with concentration: $5 \%, 10 \%$, $15 \%, 20 \%$, and potassium permanganate solution with concentration: $0.25 \%, 0.5 \%$, $0.75 \%$ and $1 \%$, aquades, surface roughness gauge, and Scanning Electron Microscope.

Coconut fiber is divided into 5 groups. One group was not treated, while four other groups were treated. First group coconut fiber is soaked in $5 \%$ sodium hydroxide solution for 3 hours. Then, it is dried in an oven at $90{ }^{\circ} \mathrm{C}$ for 5 hours. After that it was soaked in $0.25 \%$ potassium permanganate solution for 3 hours. After that it is dried in an oven at $90{ }^{\circ} \mathrm{C}$ for 5 hours. The second group coconut fiber is soaked in $10 \%$ sodium hydroxide solution for 3 hours. After that it is dried in an oven at $90{ }^{\circ} \mathrm{C}$ for 5 hours. After that it was soaked in $0.5 \%$ potassium permanganate solution for 3 hours. After that it is dried in an oven at $90{ }^{\circ} \mathrm{C}$ for 5 hours. The third group coconut fiber is soaked in a $15 \%$ sodium hydroxide solution for 3 hours. After that it is dried in an oven at $90{ }^{\circ} \mathrm{C}$ for 5 hours. After that it was immersed in $0.75 \%$ potassium permanganate solution for 3 hours. After that it is dried in an oven at $90{ }^{\circ} \mathrm{C}$ for 5 hours. The fourth group coco fiber is soaked in $20 \%$ sodium hydroxide solution for 3 hours. After that it is dried in an oven at $90{ }^{\circ} \mathrm{C}$ for 5 hours. After that it was soaked in $1 \%$ potassium permanganate solution for 3 hours. After that it is dried in an oven at $90{ }^{\circ} \mathrm{C}$ for 5 hours.

In addition, the surface roughness will be determined by using two ways namely: Scanning Electron Microscope (SEM) Vega3 Tescan for observed, and Surface Roughness Gauge Mitutoyo SJ.301 for measure of surface roughness.

Table 1. Treatment Code of Coconut Fiber.

\begin{tabular}{|c|c|}
\hline Treatment Code & Treatment \\
\hline TP & Without Treatment \\
\hline PN05 & $5 \% \mathrm{NaOH}$ \\
\hline PN10 & $10 \% \mathrm{NaOH}$ \\
\hline PN15 & $15 \% \mathrm{NaOH}$ \\
\hline PN20 & $20 \% \mathrm{NaOH}$ \\
\hline PK025 & $0,25 \% \mathrm{KMnO}_{4}$ \\
\hline PK050 & $0,50 \% \mathrm{KMnO}_{4}$ \\
\hline PK075 & $0,75 \% \mathrm{KMnO}_{4}$ \\
\hline PK100 & $1,00 \% \mathrm{KMnO}_{4}$ \\
\hline
\end{tabular}

\section{Results and discussion}

\subsection{Observed of Surface Roughness by Scanning Electron Microscope (SEM)}

Figure 1 shows the surface of coconut fiber based on SEM. The roughness of the surface of the coconut fiber shown in Fig. 1a is also different from the others. Figures 1b, 1c, 1d, and 1e show a coarser surface compared to the roughness shown in Fig. 1a. Similarly in Fig. 2, Figs. 2a, 2b, 2c, and 2d are coarser than Fig. 1a.

Figure 1 shows the surface of the coconut fiber changed after soaking in a solution of Sodium Hydroxide $(\mathrm{NaOH})$. Figures 1 b, 1c, 1d and 1e are respectively soaked in 5\%, 
$10 \%, 15 \%$, and $20 \% \mathrm{NaOH}$ solutions showing a coarser surface than Fig. 1a which is coconut fiber without treatment [8]. This suggests that the $\mathrm{NaOH}$ treatment will increase the surface roughness of the coconut fiber compared to the untreated coconut fiber $[9,10]$.

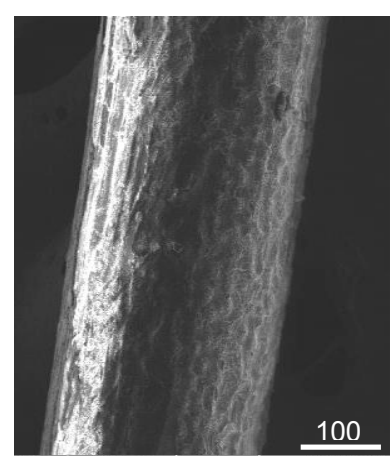

(a)

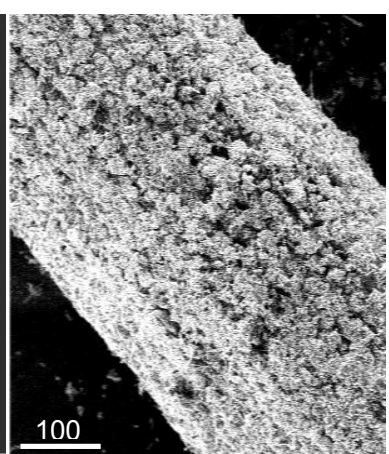

(b)

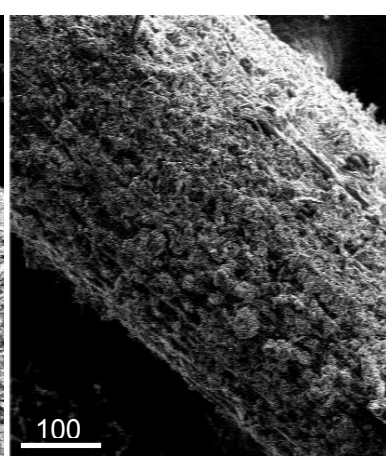

(c)

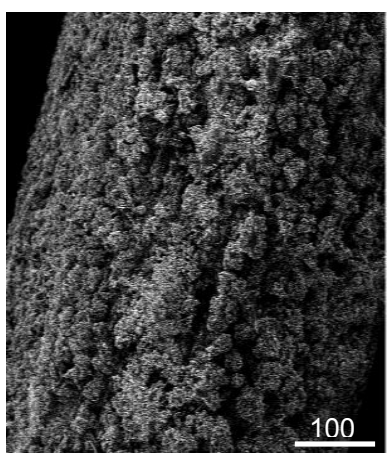

(d)

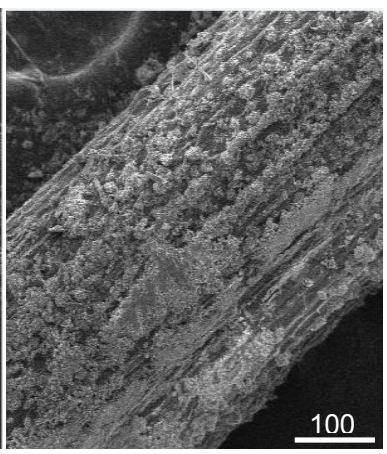

(e)

Fig. 1. Roughness of Coconut Fiber Surfaces Based on SEM. a). TP, b). PN05, c). PN10, d). PN15, e). PN20.

Similarly, Fig. 2 shows a coarser surface than Fig. 1a. Fig. 2 (2a, 2b, 2c, 2d) shows the surface of coconut fiber after treatment of potassium permanganate $\left(\mathrm{KMnO}_{4}\right)$, respectively $0.25 \%, 0.50 \%, 0.75 \%$, and $1 \%$ [11]. Fig. 2 also showed that $\mathrm{KMnO}_{4}$ treatment increased the surface roughness of coconut fiber compared with coconut fiber without treatment.

\subsection{Measured of Surface Roughness by Mitutoyo SJ.301}

Generally to know the roughness of fiber surface always use SEM [1,2,3,4]. Therefore, in this study also used the measurement directly by using the surface roughness gauge Mitutoyo SJ.301 [4, 8]. Based on the surface roughness gauge, the roughness of the surface of the coconut fiber is obtained as shown in Table 2. 


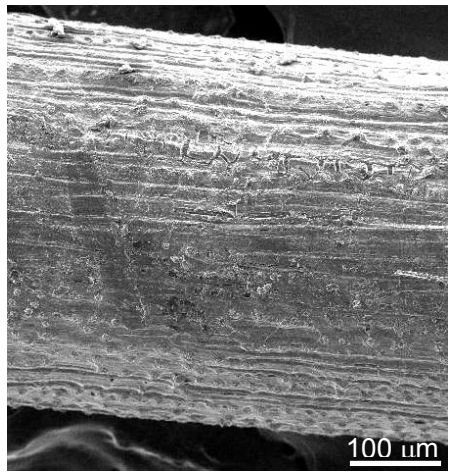

(a)

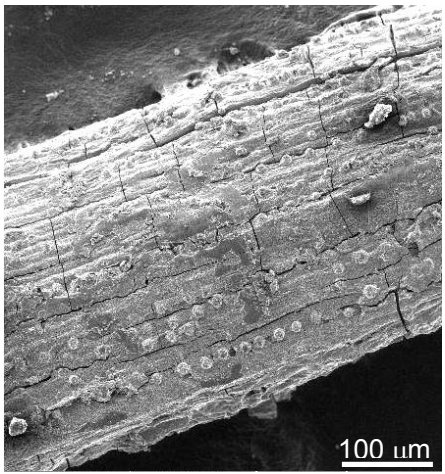

(c)

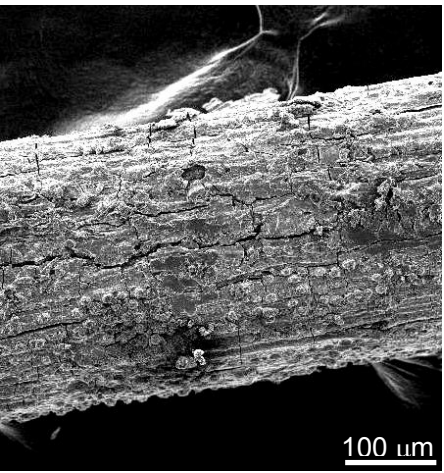

(b)

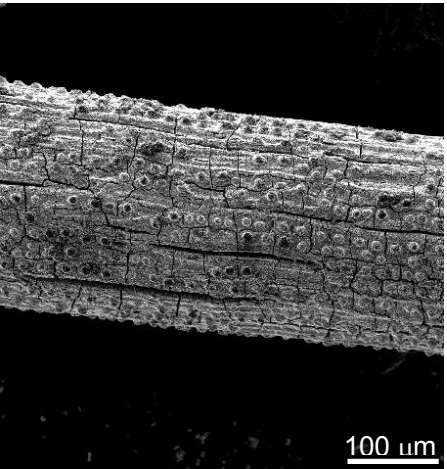

(d)

Fig. 2. Roughness of Coconut Fiber Surfaces Based on SEM. a). PK025, b). PK050, c). PK075, d). PK100.

Table 2. Roughness value of coconut fiber surface by Mitutoyo SJ.301.

\begin{tabular}{|c|c|}
\hline Treatment Code & $\mathbf{R a}(\mu \mathrm{m})$ \\
\hline TP & 1,62 \\
\hline PN05 & 3,96 \\
\hline PN10 & 3,63 \\
\hline PN15 & 3,48 \\
\hline
\end{tabular}




\begin{tabular}{|c|c|}
\hline PN20 & 2,53 \\
\hline PK025 & 3,03 \\
\hline PK050 & 2,92 \\
\hline PK075 & 3,17 \\
\hline PK100 & 2,67 \\
\hline
\end{tabular}
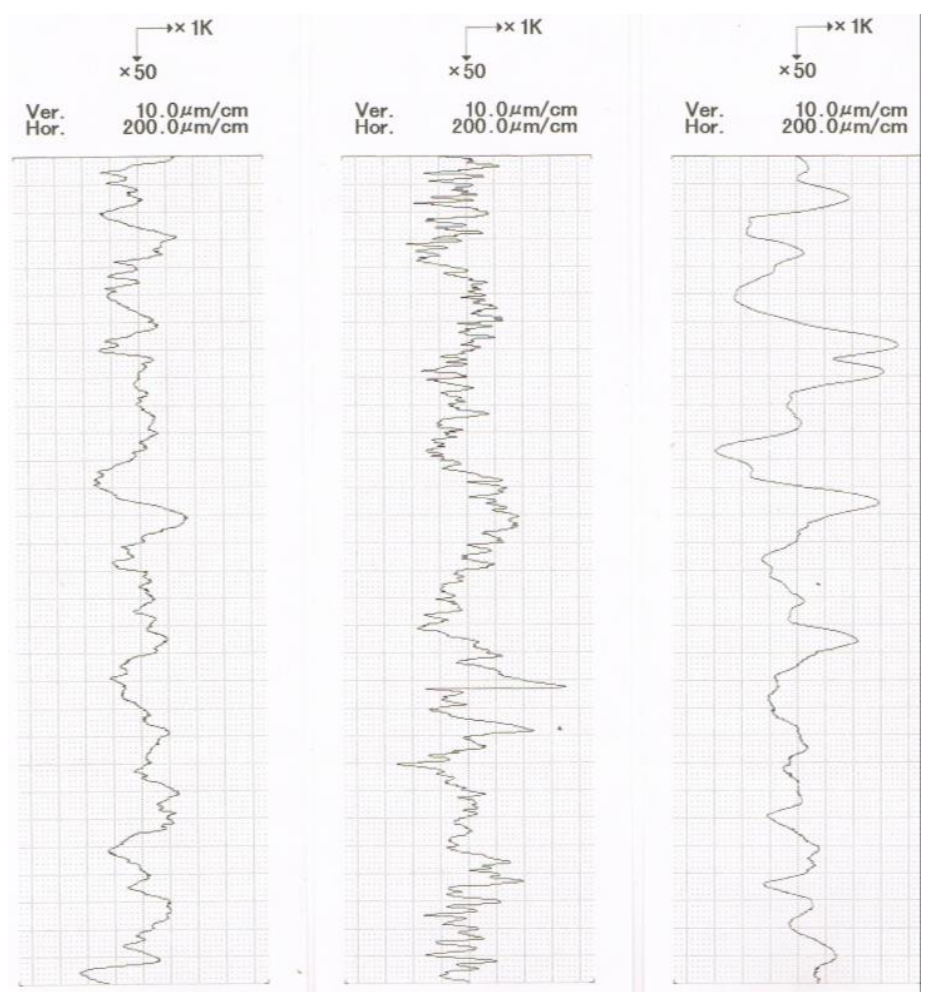

Fig. 3. Profile of roughness arithmatic of coconut fiber surface by Mitutoyo SJ.301.

The roughness of surface is generated by arithmatic average ( $\mathrm{Ra}$ ) deviations from line profiles as seen in Figure 3, where ten highest and lowest peaks are divided into the earlier sample length, then again divided by 1000 . As shown in Table 2, the treatment of sodium hydroxide, and potassium permanganate affects surface roughness. The coarse surface coir fiber roughness value of $1.62 \mu \mathrm{m}$, after being treated with sodium hydroxide coarseness surface of coconut fiber increased to $3.96 \mu \mathrm{m}$, as well as on potassium permanganate treatment the surface roughness of coconut fiber increased to $3.17 \mu \mathrm{m}$ compared to the coarse surface roughness of coconut fiber without treatment ie $1.62 \mu \mathrm{m}$. Overall surface coir fiber roughness improved after sodium hydroxide treatment and potassium permanganate treatment.

Based on the measurements of surface roughness with the Mitutoyo SJ.301 roughness gauge as shown in Table 1, it shows that chemical treatment is able to increase surface roughness, where the smallest surface roughness value is surface roughness of S2K without treatment with a roughness value of $1.62 \mu \mathrm{m}$. The roughest coir fiber surface was treated with PN05 with a roughness of $3.96 \mu \mathrm{m}$, PK075 treatment with a roughness of $3.17 \mu \mathrm{m}$.

Based on both methods used, the SEM and the Roughness Gauge method (Figure 1, Figure 2, and Table 2) give similar results. The treatment effect with $\mathrm{NaOH}$ causes the coir 
fiber surface to be coarser than the $\mathrm{KMnO}_{4}$ treatment and without treatment. This shows that the Roughness Gauge method reinforces the results obtained on the SEM method.

\section{Conclusion}

a. The treatment of coconut fiber surface with sodium hydroxide and potassium permanganate affects the coconut fiber roughness.

b. The surface of coconut fiber which has the highest surface roughness of $3.96 \mu \mathrm{m}$ was obtained in the treatment of Sodium Hydroxide with 5\% concentration. While on potassium permanganate treatment, the highest surface roughness was obtained at potassium permanganate treatment with $0.75 \%$ concentration of $3.17 \mu \mathrm{m}$.

\section{References}

1. Arsyad M., Wardana I.N.G., Pratikto Irawan Y.S. 2015, Revista Materia, 20, 01: 169177 (2015)

2. Palungan M.B., Soenoko R., Irawan Y.S., Purnowidodo A., Journal of Engineering Science and Technology. 12, 5: 1399 - 1414 (2017)

3. Arsyad M., Wardana I.N.G., Pratikto Irawan Y.S., International Journal of Applied Engineering Research, 10, 04: 9561-9570 (2015)

4. Arsyad M., ARPN Journal of Engineering and Applied Sciences, 12, 6:1870-1875 (2017)

5. Renreng I., Soenoko R., Pratikto., Irawan Y.S., Journal of Engineering Science and Technology, 12, 8: 2229 -2237 (2017)

6. Cruz J., Raul F., Procedia Engineering. 155:285 - 288 (2016)

7. Mohanty, A.K., Misra,M., Drzal,L.T., Natural Fibers, Biopolymers, And,Biocomposites. New York : CRC Press Taylor \& Francis Group (2005)

8. Husen M., Balfas M., Kamil K., ARPN Journal of Engineering and Applied Sciences, 11, 23:13681-13685 (2016)

9. Esmeraldo, M.A., Barreto, A.C.H., Freitas, J.E.B., et.al., J.Bioresources, 5, 4: 2578 2501 (2010)

10. Hemsri, S., Grieco, K., Asandei, A.D., Parnas, R.S., J.Composites, (2012)

11. Srinivasababu, N., K. Murali Mohan Rao, K.M.H.R., and Kumar, J.S., International Jornal of Engineering, 3, 4: 403 - 412 